\title{
Patterns of sexual and asexual reproduction in the brittle star Ophiactis savignyi in the Florida Keys
}

\author{
Tamara M. McGovern* \\ Department of Biological Science, Florida State University, Tallahassee, Florida 32306-1100, USA
}

\begin{abstract}
Many plant and animal species reproduce both sexually and asexually. These 2 reproductive modes are both likely to be costly and, in many species, they occur at different times of the year. Here, I present information on the sexual and asexual reproductive biology of the brittle star Ophiactis savignyi (Echinodermata, Ophiuroidea) in the Florida Keys, USA. Small brittle stars (less than $3 \mathrm{~mm}$ ) are almost always non-mature, and non-mature individuals are more likely to have recently undergone clonal division than mature brittle stars. Males appear to have a lower size threshold for sexual maturity than do females, but the sexes do not differ in the recency of clonal division. The greatest proportion of mature brittle stars was observed in the late summer through fall in all 3 years of the study. The incidence of asexual reproduction increases in the late fall through late winter. It therefore appears that brittle stars are more likely to split after the sexual reproductive season. The onset of cloning as the sexual reproductive season ends may result from differences in the time of year in which each mode confers the greatest fitness benefit or may arise from energetic trade-offs between the 2 modes of reproduction.
\end{abstract}

KEY WORDS: Asexual reproduction · Sexual reproduction · Ophiactis savignyi · Size at reproduction · Seasonality

Resale or republication not permitted without written consent of the publisher

\section{INTRODUCTION}

Many plant (Holsinger 2000) and animal (Hughes \& Cancino 1985) species reproduce both sexually and asexually. A growing number of studies has shown that asexual reproduction makes important contributions to the local population structure of many marine invertebrates (e.g. Shick et al. 1979, Ayre 1984, Stoddart 1984, Hoffmann 1986, Johnson \& Threlfall 1987, Mladenov \& Emson 1988, Lasker 1990, McFadden 1997, Uthicke et al. 1998). Despite the contribution of asexual reproduction in many species, the genetic diversity present within populations (Ayre 1984, Stoddart 1984, Hoffmann 1986, Mladenov \& Emson 1990, Coffroth et al. 1992, McFadden 1997, Uthicke et al. 1998) attests to the importance of sexual reproduction.

${ }^{*}$ Present address: Friday Harbor Laboratories, 620 University Rd, Friday Harbor, Washington 98250, USA.

E-mail: tmmcgov@u.washington.edu
Sexual reproduction typically requires a major energetic investment (see e.g. Lawrence 1987 for a review of investment by echinoderms), and division must also be costly, requiring resources for the creation and maintenance of the new clonemate when clonemates remain attached, or for repair or regeneration of lost body parts when clonemates are separated. The existence of 2 costly modes of reproduction introduces the potential for conflict over the allocation of resources, but this conflict could be mitigated by the temporal separation of sexual and asexual reproduction. In many species, the 2 modes of reproduction occur at different times of the year, and the peak of asexual activity typically follows that of sexual maturity (Crozier 1920, Sebens 1981, 1982, Chao et al. 1993, Chao \& Tsai 1995, Uthicke 1997).

Both sexual and asexual reproduction have been reported in the brittle star Ophiactis savignyi. O. savignyi is a small bodied species that ranges throughout the world in the tropics (Mladenov \& Emson 1990, 
Chao \& Tsai 1995). It frequently lives in association with marine sponges, where it can occur in high densities (Mladenov \& Emson 1988, Chao \& Tsai 1995). The global distribution and large local populations led Clark (1946) to describe O. savignyi as 'the most common brittle star in the world'. Individuals likely feed on both detritus and suspended material (Hendler et al. 1995).

Ophiactis savignyi is dioecious, and at least sperm are broadcast into the water column (pers. obs.). It is likely that eggs are also broadcast because brooded embryos have never been reported. Based on egg size, larvae are presumed to feed in the plankton (Chao \& Tsai 1995, P. V. Mladenov pers. comm.) prior to settlement. In natural populations of this species, there are many small clones rather than only a few large clones (T. McGovern unpubl.), indicating that recruitment of sexually produced offspring is non-negligible in the life history of this species.

Individuals of Ophiactis savigni clone by disc fission, in which a normally 6 armed individual divides across its central disc. Each half then regenerates the missing portion of the disc and the 3 lost arms (Emson \& Wilkie 1980). There is some evidence that fission is under internal control in echinoderms, although external stimuli such as the stress associated with bringing animals into the lab have also been know to initiate division (reviewed in Mladenov 1996). Chao \& Tsai (1995) reported a temporal separation between the sexual reproductive season and the peak occurrence of fission in Taiwan. Their study lasted only a single year, however, leaving questions as to the repeatability of their findings.

In this paper, I present several years worth of data on the sexual and asexual reproductive biology of Ophiactis savignyi from the Florida Keys. I examine the associations of sexual and asexual reproduction with body size and sex. Finally, I examine patterns of seasonality in both reproductive modes and in the presence of recruits and discuss some factors that may influence the relative timing of sexual and asexual reproductive seasons in this species.

\section{MATERIALS AND METHODS}

Individuals of Ophiactis savignyi were collected approximately every 4 to 8 wk from March 1996 through October 1998 from areas around Long Key, Florida. In each sampling period, I hand collected 4 to 47 sponges (primarily Tedania ignis, a sponge species in which O. savignyi is common), finely dissected each sponge, and removed all brittle stars residing within the sponge (hereafter termed a 'population'). Once removed from the sponge host, the brittle stars were anesthetized in magnesium chloride (Mladenov et al. 1983), and I made several observations for each including the diameter of the central disc, sex and the lengths of all arms.

The diameter of the central disc of each brittle star is easily measured and can be obtained without killing the animal. To determine if disc diameter was a good measure of body size, I measured both disc diameter and dry weight for 334 individuals in the fall of 1997. The diameter at the widest part of the disc was measured to the nearest $0.5 \mathrm{~mm}$ using a dissecting microscope. Each brittle star was then placed on a preweighed piece of aluminum foil and dried in an oven at $210^{\circ} \mathrm{C}$ for at least $48 \mathrm{~h}$. A final mass was recorded when the samples had completely dried, as indicated by consistent measurements on repeated days. All weights were measured using a OHAUS Analytical Plus balance to the nearest $0.1 \mathrm{mg}$. Once it was determined that disc diameter could be used as a measure of body size, diameters were compared using an ANOVA with planned contrasts between brittle stars with and without gonads present, and between females and males.

I determined the sex of each individual by visual inspection of the gonads (when present). Testes and ovaries were easily distinguished on the basis of color and structure: testes are white and have a distinctive serpentine structure, whereas ovaries are brown with large, clearly visible egg cells. In brittle stars with large, well-developed gonads, the color and structure of the gonads were often visible through the skin. In smaller individuals, sex was ascertained by minor dissection into the bursal cavity. It was not possible to assess for every brittle star with gonads whether the gametes were capable of fertilization at the time they were collected, but in some cases, I observed the gametes under a compound microscope. In all cases where testes were observed, the sperm appeared active. The ripeness of eggs is more difficult to gauge in ophiuroids because the chemical stimulus required for egg maturation (breakdown of the germinal vesicle) may immediately precede the stimulus that induces spawning, as is the case with asteroids (Kanatani \& Nagahama 1983). I therefore considered all brittle stars with apparently healthy gonads 'mature' for the purpose of this study. To examine seasonal patterns in the proportion of mature brittle stars, I examined the average proportion mature from the populations collected in each sampling period.

To determine if females and males differed in their investment in sexual reproduction, I measured the mass invested in gonads by the mature brittle stars for whom mass was obtained in October 1997. For 31 females and 51 males, I removed the gonads using a pair of fine forceps and obtained dry weights, as described above, for the gonads and the body separately. I deter- 
mined whether the sexes differed in the relationship between gonad mass and body mass using an ANCOVA.

I used changes in the proportion of brittle stars with disc diameters of $1 \mathrm{~mm}$ or less to gauge the timing of sexual recruitment into populations of Ophiactis savignyi. As with the estimates of the proportion of mature brittle stars, the estimate of the proportion of brittle stars considered to be sexual recruits in each sampling period represents the average of the populations collected during that month.

The ratio of the lengths of the 3 shortest adjacent arms to that of the 3 longest adjacent arms was used as a relative measure of the recency of division (Mladenov \& Emson 1988). Low ratios signify a large difference between the short and long arm lengths and indicate recent division. Length ratios approaching 1 indicate arms of even lengths and a relatively greater time since division. Arms that had clearly been recently broken were not considered when calculating average arm lengths. If all 3 short or long arms on any individual were broken, I excluded that individual from analyses of arm length ratios. In all groups (nonmatures, females and males), only about $5 \%$ of the brittle stars had to be excluded from the analyses of arm length ratios. Average arm length ratios were compared using an ANOVA with planned contrasts between non-mature and mature brittle stars and between females and males.

To examine seasonal trends in division, I plotted the average arm length ratio of the populations sampled in each time period. Because very few mature brittle stars were available, particularly during winter and spring months (see below), these averages represent the arm length ratios of all animals regardless of maturity. Because the timing of division in mature brittle stars was also of interest, I present information on the timing of division in mature brittle stars from an experiment examining the division rates of mature individuals (see

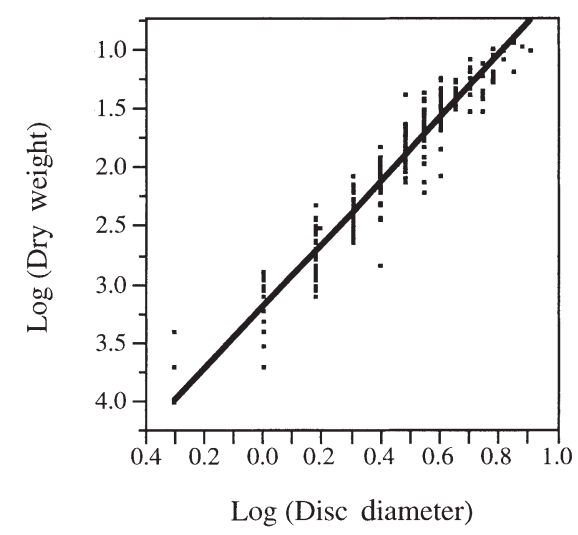

Fig. 1. Dry weight as a function of maximum disc diameter

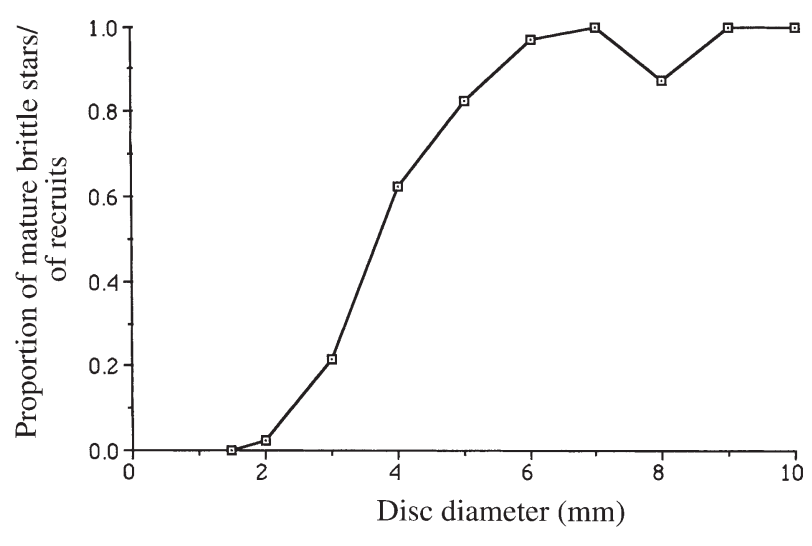

Fig. 2. Proportion of brittle stars with gonads as a function of disc diameter

McGovern 2002). This experiment was begun in October 1997 and terminated in June of 1998, and therefore covers only a portion of the time encompassed by the survey described above, but only mature brittle stars were used in the experiment.

\section{RESULTS}

The density of brittle stars within sponge hosts averaged 77 ind. $\mathrm{l}^{-1}$ of sponge material but was quite variable (range 3 to 579 ind. $\mathrm{l}^{-1}$ ). Individual body size ranged from 0.5 to $10 \mathrm{~mm}$ disc diameter. Brittle stars with disc diameters up to $11.5 \mathrm{~mm}$ have been observed in other collections (pers. obs.). Disc diameter was highly correlated with dry weight $\left(\mathrm{r}^{2}=0.932, \mathrm{p}<0.001\right.$, Fig. 1), so disc diameters were used in all comparisons of body size.

Mature brittle stars were significantly larger than non-mature ones $(p<0.001$, Table 1$)$. Animals smaller than $3 \mathrm{~mm}$ diameter were rarely sexually mature, whereas most brittle stars over $4 \mathrm{~mm}$ were mature (Fig. 2). The distributions of body size for mature females and males were nearly completely overlapping but a relatively greater proportion of males were in smaller size

Table 1. Disc diameters (mm) and arm length ratios for nonmature and mature brittle stars from March 1996 through October 1998. Arm length ratio data are reported for fewer brittle stars because this information could not be calculated for all individuals for which disc diameters were available

\begin{tabular}{|lrrrr|}
\hline & $\mathrm{n}$ & $\begin{array}{c}\text { Disc diameter } \\
\text { mean (SD) }\end{array}$ & $\mathrm{n}$ & $\begin{array}{c}\text { Arm length ratio } \\
\text { mean (SD) }\end{array}$ \\
\hline Non-mature & 8709 & $1.5(0.73)$ & 8295 & $0.48(0.28)$ \\
Female & 167 & $4.63(1.42)$ & 158 & $0.67(0.32)$ \\
Male & 346 & $4.02(1.28)$ & 329 & $0.66(0.30)$ \\
& & & & \\
\hline
\end{tabular}


classes (Fig. 3). This was reflected in the significantly smaller average size of mature males relative to that of mature females $(p<0.001)$. In any given sampling period, the proportion of sexually mature brittle stars was low (1.5 to $16.1 \%$, Fig. $4 \mathrm{~A})$.

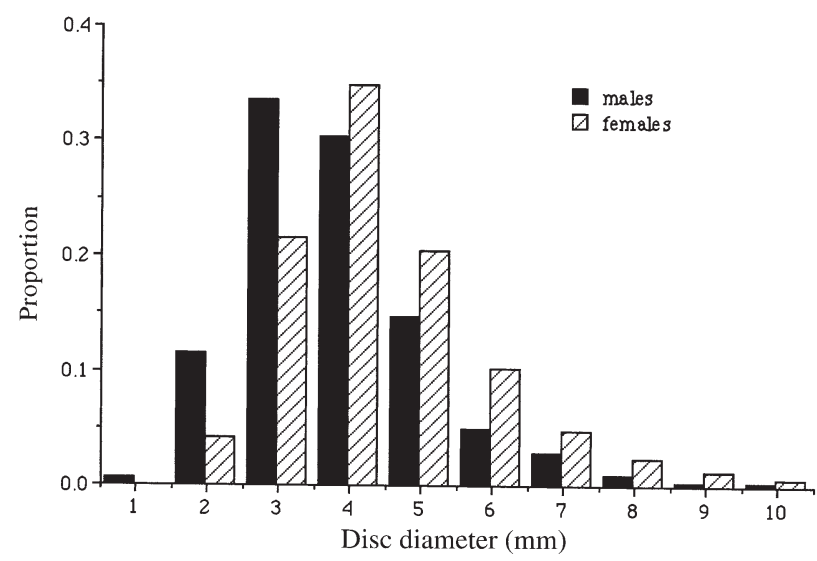

Fig. 3. Size distribution of mature females (hatched bars) and males (solid bars)
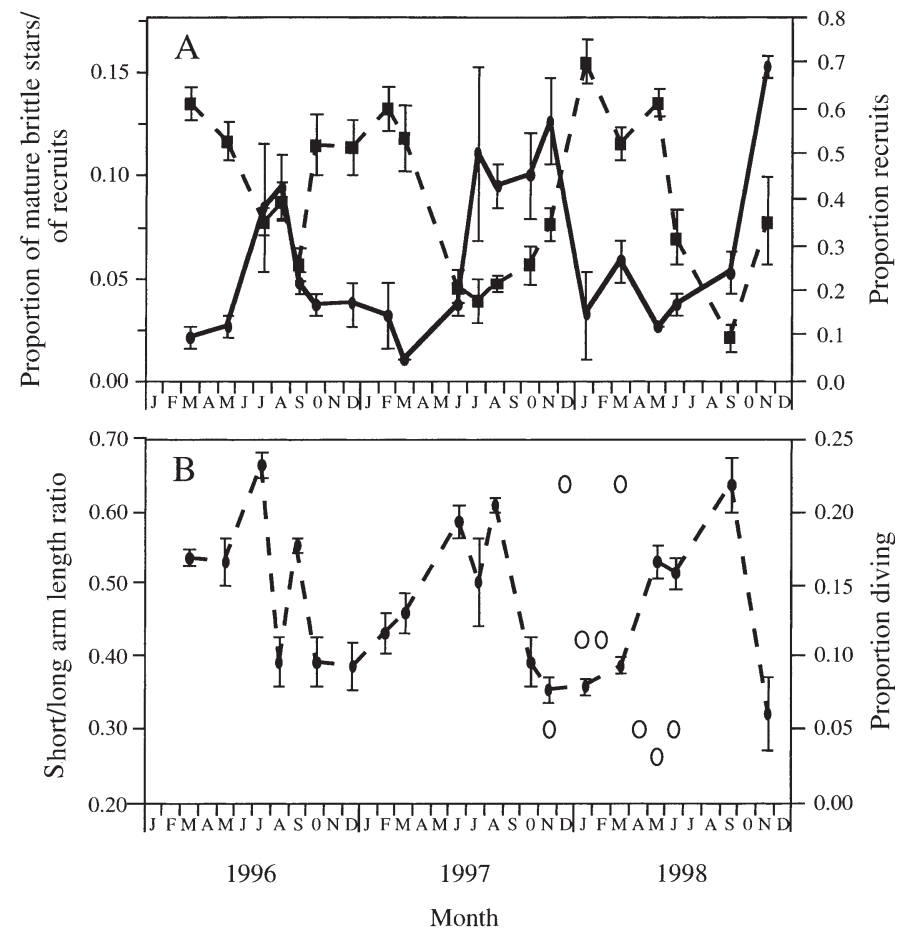

Fig. 4. (A) Proportion of mature brittle stars $(\bullet,-)$ and proportion of samples considered recruits ( $\mathbf{\square},---)$ in sampling periods from March 1996 through October 1998; (B) the arm length ratios for the same sampling month (•,---). Increasing incidence of division is represented by arm length ratios approaching 0 . Also shown in (B) are the proportion of mature brittle stars dividing in a field experiment (O). Means and standard errors are shown for each period
The relationship between body weight and gonad weight is shown in Fig. 5. Gonad weight increased with body weight in both sexes (females: $\mathrm{r}^{2}=0.57, \mathrm{n}=$ 31; males: $\mathrm{r}^{2}=0.53, \mathrm{n}=51 ; \mathrm{p}<0.001$ for both), and the relationship between body mass and gonad mass was similar for females and males (i.e. the slopes are homogeneous, $\mathrm{p}=0.684$ ). Although females tended to have a greater allocation to gonad mass than males for any given body mass, this difference was not significant $(p=0.277)$. The arm length ratios of females and males did not differ $(p=0.709$, Table 1$)$, but non-mature brittle stars were significantly more likely than mature ones to have recently divided $(p<0.001)$.

There appeared to be seasonal trends in the proportion of brittle stars that was mature (Fig. 4A) and the proportion of brittle stars classified as sexual recruits (Fig. 4A). The greatest proportion of mature animals was typically observed from the late summer through fall. The proportion of recruits increased towards the end of, and remained high for several months following, the sexual reproductive season.

Clonal division appeared to be more frequent in the late fall and winter, as evidenced by the low arm length ratios in these months (Fig. 4B). The arm length ratios were higher (i.e. relatively fewer brittle stars had recently undergone division) in the spring and summer at approximately the same time as when more brittle stars were becoming sexually mature. The division rates of mature brittle stars from the experiment described in McGovern (2002) were highest after the end of the sexual reproductive cycle in 1997 (Table 2, Fig. 4B).

\section{DISCUSSION}

It appears that individuals of Ophiactis savignyi have to reach a size threshold in order to attain sexual maturity. Few brittle stars smaller than $3 \mathrm{~mm}$ disc diameter

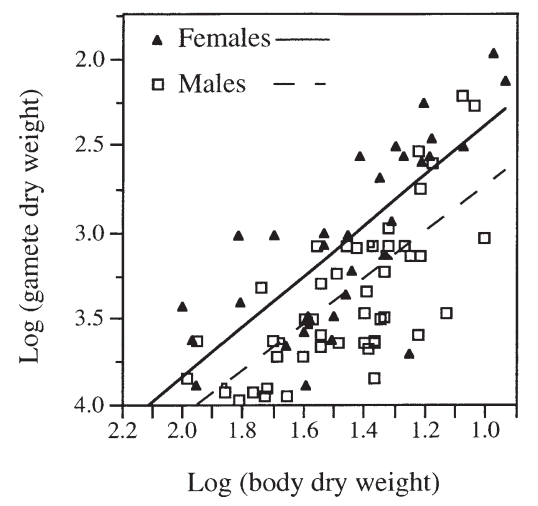

Fig. 5. Gonad weight as a function of body weight for females $(\boldsymbol{\Lambda},-)$ and males $(\square,---)$ 
were mature, but most large individuals had gonads. Size thresholds for sexual maturity are common in many organisms, including plants (Bierzychudek 1984, Dupont \& Kato 1999) and marine invertebrates (Karlson 1986, Mladenov \& Emson 1988, Kapela \& Lasker 1999, Smith \& Hughes 1999).

Females and males exhibited slight but significant differences in the sizes at which they reached maturity. In some cases (see examples in Charnov 1982), differences in the size distribution of females and males has indicated protandry. Protandry is unlikely in this species for several reasons. First, most echinoderms are gonochoristic (Lawrence 1987). Second, although the average male was significantly smaller than the average female, the size distributions were completely overlapping and the largest males and females were the same size. Third, in several years of observing Ophiactis savignyi, I have never seen one change sex. Fourth, in genetic analyses of clonal structure, females and males have never been assigned to the same clone (T. McGovern unpubl.).

Females have been reported to have larger reproductive size thresholds in a number of non-protandrous plant (Bawa et al. 1982, Lovett Doust \& Lovett Doust 1988) and animal (Ayre 1984, Gillanders et al. 1999) species, and these differences are frequently attributed to a greater investment in sexual reproduction by females (Darwin 1877, Garcia \& Antor 1995, reviewed in Lloyd \& Webb 1977). I did not, however, find evidence for differences between females and males in sexual reproductive investment in Ophiactis savignyi: females tended to have a greater mass invested in gonads at any given size relative to males, but this difference was not significant. It is therefore unclear why females and males of this species would differ in their reproductive size thresholds. It is possible that the small differences in the investment patterns of females and males (Fig. 5) are biologically important but statistically indiscernible: despite sample sizes of 31 females and 51 males, the statistical power to discriminate between patterns of sexual allocation was low (0.22).

It is also possible that gonad mass alone may not be the most appropriate measure of investment. For example, if sperm and egg production were limited by different resources (e.g. protein vs lipids), and small animals had greater access to resources that limited sperm production, males may be able to reach maturity at smaller sizes. Some difference in the composition of gonads of testes and ovaries have been reported for echinoderms (reviewed in Levitan 1998). Whether such differences in gonad composition and resource availability occur in Ophiactis savignyi is unknown, but it is likely that small and large brittle stars differ in the prey available to them. Whereas all individuals are likely to obtain some nutrition by grazing detritus from the surface of the sponge (Hendler et al. 1995), observational studies suggest that only large brittle stars extend their arms to collect prey available in the water column (pers. obs.). Small brittle stars could therefore have reduced access to certain types of resources. If these resources limited egg production preferentially, the differences between females and males in the sexual reproductive size thresholds might be explained.

Non-mature brittle stars were more likely to have recently undergone asexual reproduction than mature animals. A greater incidence of cloning in non-mature animals has been observed in other species as well (reviewed in Emson \& Wilkie 1980, Crump \& Barker 1985). It is possible that the process of division and regeneration is structurally 'easier' for small animals, though no studies have demonstrated differences in the mechanical properties of small and large individuals (Emson \& Wilkie 1980). It is also likely that, because they are below the sexual reproductive size threshold, small animals are not subject to any of the immediate energetic trade-offs between sexual and asexual reproduction that mature animals may experience (Emson \& Wilkie 1980).

The arm length ratios of females and males did not differ, suggesting that the sexes did not differ in the recency of asexual reproduction. This is in contrast to another study (McGovern 2002) in which the division rates of females followed through time were shown to be lower than those of males. Because the current study was unable to follow individuals through time, but rather surveyed different animals in each of the sampling periods, it is difficult to ascertain why the 2 studies differed.

There appeared to be seasonal patterns to both sexual and asexual reproduction. There was some interannual variation and temporal overlap, but the greatest proportion of mature individuals was seen between late summer and late fall. The proportion of small $(\leq 1 \mathrm{~mm})$ brittle stars, considered here to be recruits, increased toward the end of the period when the great- 
est proportion of brittle stars was mature and remained high for several months following the end of the sexual reproductive season. This patterns suggests a planktonic phase of several months, assuming that the recruits were locally produced.

The incidence of division was highest in the mid to late fall through early spring. Fission in other echinoderm species has been shown to occur seasonally (Mladenov et al. 1986) and Chao \& Tsai (1995) reported seasonal peaks in both sexual and asexual reproduction in Ophiactis savignyi in Taiwan. In their study, the peaks occur earlier in the year than what is reported here, possibly as a result of the many environmental differences that likely exist between the Florida Keys and Taiwan.

Seasonal separation of sexual and asexual reproduction has been reported for Ophiactis savignyi (Chao \& Tsai 1995) and other species (Crozier 1920, Sebens 1981, 1982, Chao et al. 1993, Uthicke 1997) and the peak sexual activity generally preceded the onset of asexual reproduction, as was found in this study. There are several potential explanations for the relative timing of sexual and asexual reproduction in this species. First, the timing of asexual and sexual reproduction may reflect competition for energetic reserves between the 2 reproductive modes. Such trade-offs between the various components that contribute to fitness are central to life history theory and have the result that an organism cannot simultaneously maximize its allocation to more than 1 of these functions (Gasser et al. 2000). Sexual reproduction typically requires a major energetic investment (reviewed in Lawrence 1987), and division must also be costly, particularly for species such as $O$. savignyi that must regenerate half their bodies following cloning. Tradeoffs between sexual reproduction and division may arise if resources for asexual reproduction must be diverted away from the production of gametes (Emson \& Wilkie 1980) or if cloning results in the division of a single large individual into several small clonemates that are less likely to be able to sustain the energetic costs of sexual reproduction (e.g. Hughes \& Jackson 1985, Karlson 1986, Smith \& Hughes 1999). Trade-offs between sexual and asexual reproduction have been suggested in a variety of other clonal taxa (e.g. Yund et al. 1997, Ronsheim \& Bever 2000).

Energetic trade-offs between sexual and asexual reproduction could influence their relative timing in 2 ways. Natural selection may have optimized the timing of each reproductive mode such that energetic competition would be minimized. Alternatively, the decline in the proportion of sexually mature individuals (in a wide range of species) in the population could be a direct consequence of the increasing incidence of division: as animals begin to divide, the energetic demands of cloning may actually cause the reversion of mature animals to a non-mature state. Division appears to increase before the proportion of mature animals begins to drop, perhaps supporting this possibility. Echinoderms have been shown to resorb gonads in other conditions (e.g. starvation) that would require the redirection of energy to other functions (Lawrence 1987). In both sexes of Ophiactis savignyi, but particularly in females, division of mature brittle stars has been shown to cause 1 or both halves to lose sexual capabilities (McGovern 2002), so it is possible that the onset of division effectively terminates the breeding season by diverting the resources necessary to sustain gonad production and development.

The relative timing of sexual and asexual reproduction may also have little to do with the interaction between the 2 reproductive modes. Temporal patterns of division and sexual reproduction may be shaped by a variety of factors, including selective pressures acting to increase survival of adults and/or offspring (Gerritsen 1980) or a compromise between these concerns (Muenchow 1978). Sebens (1979) has suggested that seasonal patterns of fission in the anemone Anthopleura elegantissima reflect the energetic dynamics of body size and prey capture. Mladenov (1996) suggests that fission in some echinoderm species is timed to occur when water temperature is warmest and regeneration times would presumably be reduced. The timing of offspring or gamete release could be related to the availability of the food sources used by the developing young (Himmelman 1981) or to the avoidance of predators (Harrison et al. 1984). Temporal separation of clonal and sexual reproduction may therefore reflect differences in the time of year at which each mode of reproduction confers the greatest fitness, irrespective of the interaction between the two.

This study indicated that there were single yearly peaks of both asexual and sexual reproduction in Florida Keys populations of Ophiactis savignyi. Although the proportion of brittle stars with gonads was never high, there does appear to be a pulse of recruitment following the sexual peak in each year, indicating that sexual reproduction was successful. Females and males mature at different sizes but do not significantly differ in the mass invested in gonadal material at any given body size. There is evidence that non-mature brittle stars were more likely to have recently divided, possibly because they were not subject to the energetic demands of sexual reproduction.

Acknowledgements. I would like to thank the staff of the Keys Marine Lab on Long Key Florida for support of this work and occasional collections of animals. Many helpful comments were provided by R. Ellington, D. Levitan, K. McGhee, M. Mesterton-Gibbons, P. Munguia, D. Simberloff, C. Swanson, 
J. Travis and several anonymous reviewers. This work was supported by a grant from the Houston Underwater Club Seaspace program and by the Florida Institute of Oceanography who provided housing and equipment at the Keys Marine Lab.

\section{LITERATURE CITED}

Ayre DJ (1984) The effects of sexual and asexual reproduction on geographic variation in the sea anemone Actinia tenebrosa. Oecologia 62:222-229

Bawa KS, Keegan CR, Voss RH (1982) Sexual dimorphism in Aralia nudicaulis L. (Araliaceae). Evolution 36:371-378

Bierzychudek P (1984) Determinants of gender in Jack-inthe-pulpit: the influence of plant size and reproductive history. Oecologia 65:14-18

Chao SM, Tsai CC (1995) Reproduction and population dynamics of the fissiparous brittle star Ophiactis savignyi (Echinodermata: Ophiuroidea). Mar Biol 124:77-83

Chao SM, Chen CP, Alexander PS (1993) Fission and its effect on populations structure of Holothuria atra (Echinodermata: Holothuroidea) in Taiwan. Mar Biol 116:109-115

Charnov EL (1982) The theory of sex allocation. Princeton Univ Press, Princeton, NJ

Clark HL (1946) The echinoderm fauna of Australia: its composition and origin. Carnegie Inst Washington Publ 566:1-567

Coffroth MA, Lasker HR, Diamond ME, Bruenn JA, Bermingham E (1992) DNA fingerprints of a gorgonian coral: a method for detecting clonal structure in a vegetative species. Mar Biol 114:317-325

Crozier WJ (1920) Notes on some problems of adaptation. 2. On the temporal relations of asexual propagation and gametic reproduction in Coscinasterias tenuispina: with a note on direction of progression and on the significance of the madreporites. Biol Bull 34:116-129

Crump RG, Barker MF (1985) Sexual and asexual reproduction in geographically separated population of the fissiparous asteroid Coscinasterias calamaria (Gray). J Exp Mar Biol Ecol 88:109-127

Darwin C (1877) The different forms of flowers on plants of the same species. J Murray, London

Dupont YL, Kato M (1999) Sex ratio variation in dioecious plant species: a comparative ecological study of six species of Lindera (Lauraceae). Nord J Bot 19:529-540

Emson RH, Wilke IC (1980) Fission and autotomy in Echinoderms. Oceanogr Mar Biol Annu Rev 18:155-250

Garcia MB, Antor RJ (1995) Sex ratio and sexual dimorphism in the dioecious Borderea pyrenaica. Oecologia 101:59-67

Gasser M, Kaiser M, Berrigan D, Stearns SC (2000) Life history correlates of evolution under high and low adult mortality. Evolution 54:1260-1272

Gerritsen J (1980) Sex and parthenogenesis in sparse populations. Am Nat 115:718-742

Gillanders BM, Ferrell DJ, Andrew NL (1999) Size at maturity and seasonal changes in gonad activity of yellowtail kingfish (Seriola lalandi: Carangidae) in New South Wales, Australia. NZ J Mar Freshw Res 33:457-468

Harrison PL, Babcock RC, Bull GD, Oliver JK, Wallace CC, Willis BL (1984) Mass spawning in tropical reef corals. Science 233:1186-1189

Hendler G, Miller JE, Pawson DL, Kier PM (1995) Sea stars. sea urchins and allies: Echinoderms of Florida and the Caribbean. Smithsonian Institution Press, Washington DC

Himmelman JH (1981) Synchronization of spawning in marine invertebrates by phytoplankton. In: Clark WH Jr,
Adams TS (eds) Advances in invertebrate reproduction. Elsevier Science Publications, New York, p 3-19

Hoffmann RJ (1986) Variation in contributions of asexual reproduction to the genetic structure of populations of the sea anemone Metridium senile. Evolution 40:357-365

Holsinger KE (2000) Reproductive systems and evolution in vascular plants. Proc Nat Acad Sci 97:7037-7042

Hughes RN, Cancino JM (1985) An ecological overview of cloning in Metazoan. In: Jackson JBC, Buss LW, Cook RE (eds) Population biology and evolution of clonal organisms. Yale Univ Press, New Haven, p 153-186

Hughes TP, Jackson JBC (1985) Population dynamics and life histories of foliaceous corals. Ecol Monogr 55:141-166

Johnson MS, Threlfall TJ (1987) Fissiparity and population genetics of Coscinasterias calamaria. Mar Biol 93:517-525

Kanatani H, Nagahama Y (1983) Echinodermata. In: Adiyodi KG, Adiyodi RG (eds) Reproductive biology of invertebrates, Vol 1. Wiley-Liss, New York, p 611-654

Kapela W, Lasker HR (1999) Size-dependent reproduction in the Caribbean gorgonian Pseudoplexaura porosa. Mar Biol 135:107-114

Karlson RH (1986) Disturbance, colonial fragmentation, and size-dependent life history variation in two coral reef cnidarians. Mar Ecol Prog Ser 28:245-249

Lasker HR (1990) Clonal propagation and population dynamics of a gorgonian coral. Ecology 71:1578-1589

Lawrence J (1987) A functional biology of echinoderms. Johns Hopkins Univ Press, Baltimore

Levitan DR (1998) Sperm competition, gamete competition, and sexual selection in external fertilizers. In: Birkhead TR, Moller AP (eds) Sperm competition and sexual selection. Academic Press, San Diego, p 175-217

Lloyd DG, Webb CJ (1977) Secondary sex characters in plants. Bot Rev 43:177-216

Lovett Doust J, Lovett Doust L (1988) Modules of production and reproduction in a dioecious clonal shrub, Rhus typhina. Ecology 69:741-750

McFadden CS (1997) Contributions of sexual and asexual reproduction to population structure in the soft coral Alcyonium rudyi. Evolution 51:112-126

McGovern TM (2002) Sex ratio bias and clonal reproduction in the brittle star Ophiactis savignyi. Evolution (in press)

Mladenov PV (1996) Environmental factors influencing asexual reproductive processes in echinoderms. Oceanol Acta 19:227-235

Mladenov PV, Emson RH (1988) Density, size structure and reproductive characteristics of fissiparous brittle stars in algae and sponges: evidence for interpopulational variation in levels of sexual and asexual reproduction. Mar Ecol Prog Ser 42:181-194

Mladenov PV, Emson RH (1990) Genetic structure of populations of two closely related brittle stars with contrasting sexual and asexual life histories, with observations on the genetic structure of a second asexual species. Mar Biol 104:265-274

Mladenov PV, Emson RH, Colpit LV, Wilkie IC (1983) Asexual reproduction in the West Indian brittle star Ophicomella ophiactoides (H. L. Clark) (Echinodermata: Ophiuroidea). J Exp Mar Biol Ecol 72:1-23

Mladenov PV, Carson SF, Walker CW (1986) Reproductive ecology of an obligately fissiparous population of the sea star Stephanasterias albula (Stimson). J Exp Mar Bio Ecol 96:155-175

Muenchow G (1978) A note on the timing of sex in asexual/ sexual organisms. Am Nat 112:774-779

Ronsheim ML, Bever JD (2000) Genetic variation and evolutionary trade-offs for sexual and asexual reproductive 
modes in Allium vineale (Lillaceae). Am $\mathrm{J}$ Bot 87: 1769-1777

Sebens KP (1981) Reproductive ecology of the intertidal sea anemones Anthopleura xanthogrammica (Brandt) and A. elegantissima (Brandt): body size, habitat, and sexual reproduction. J Exp Mar Biol Ecol 54:225-250

Sebens KP (1982) Asexual reproduction in Anthopleura elegantissima (Anthozoa: Actiniaria): seasonality and spatial extent of clones. Ecology 63:434-444

Shick JM, Hoffmann RJ, Lamb AN (1979) Asexual reproduction, population structure, and genotype-environment interactions in sea anemones. Am Zool 19:699-713

Smith LD, Hughes TP (1999) An experimental assessment of survival, re-attachment and fecundity of coral fragments.

Editorial responsibility: Ronald Karlson (Contributing Editor), Newark, Delaware, USA
J Exp Mar Biol Ecol 235:147-164

Stoddart JA (1984) Genetical structure within populations of the coral Pocillopora damicornis. Mar Biol 81:19-30

Uthicke S (1997) Seasonality of asexual reproduction in Holothuria (Halodeima) atra, H. (H.) edulis and Stichopus chloronotus (Holothuroidea: Aspidochirotida) on the Great Barrier Reef. Mar Biol 127:435-441

Uthicke S, Benzie JAH, Ballment E (1998) Genetic structure of fissiparous populations of Holothuria (Halodeima) atra on the Great Barrier Reef. Mar Biol 132:141-151

Yund PO, Marcum Y, Stewart-Savage J (1997) Life history variation in a colonial ascidian: broad-sense heritabilities and trade-offs in allocation to asexual growth and male and female reproduction. Biol Bull 192:290-299

Submitted: May 17, 2001; Accepted: September 8, 2001 Proofs received from author(s): March 5, 2002 